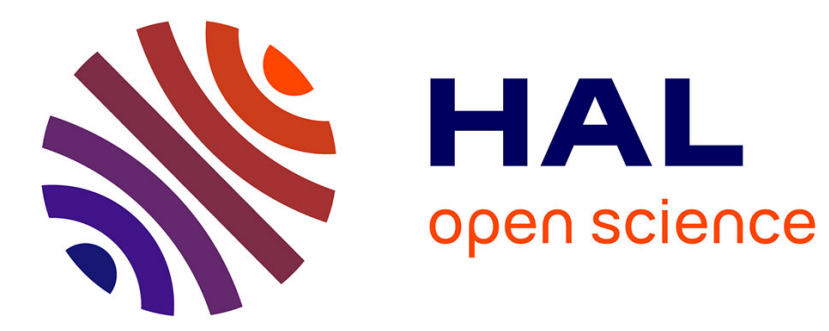

\title{
Evolution of oxide film on the internal porosity of Ti-30Nb-13Ta-2Mn alloy foam
}

Carolina Guerra, Mamié Sancy, Magdalena Walczak, Daniela Silva, Carola Martínez, Bernard Tribollet, Claudio Aguilar

\section{- To cite this version:}

Carolina Guerra, Mamié Sancy, Magdalena Walczak, Daniela Silva, Carola Martínez, et al.. Evolution of oxide film on the internal porosity of Ti-30Nb-13Ta-2Mn alloy foam. Electrochimica Acta, 2018, 283, pp.676 - 682. 10.1016/j.electacta.2018.05.010 . hal-01835560

\section{HAL Id: hal-01835560 \\ https://hal.sorbonne-universite.fr/hal-01835560}

Submitted on 11 Jul 2018

HAL is a multi-disciplinary open access archive for the deposit and dissemination of scientific research documents, whether they are published or not. The documents may come from teaching and research institutions in France or abroad, or from public or private research centers.
L'archive ouverte pluridisciplinaire HAL, est destinée au dépôt et à la diffusion de documents scientifiques de niveau recherche, publiés ou non, émanant des établissements d'enseignement et de recherche français ou étrangers, des laboratoires publics ou privés. 
Evolution of oxide film on the internal porosity of Ti-30Nb-13Ta-2Mn alloy foam

Carolina Guerra ${ }^{1}$, Mamié Sancy ${ }^{2,3^{*}}$, Magdalena Walczak ${ }^{1,3}$, Daniela Silva ${ }^{4}$, Carola Martínez ${ }^{5}$, Bernard Tribollet ${ }^{6}$ and Claudio Aguilar ${ }^{4}$

${ }^{1}$ Departamento de Ingeniería Mecánica y Metalúrgica, Escuela de Ingeniería, Pontificia Universidad Católica de Chile, Av. Vicuña Mackenna 4860, Macul, Santiago, Chile.

${ }^{2}$ Escuela de Construcción Civil, Facultad de Ingeniería, Pontificia Universidad Católica de Chile, Av. Vicuña Mackenna 4860, Macul, Santiago, Chile.

${ }^{3}$ Centro de Investigación en Nanotecnología y Materiales Avanzados "CIENUC", Pontificia Universidad Católica de Chile, Av. Vicuña Mackenna 4860, Macul, Santiago, Chile

${ }^{4}$ Departamento de Ingeniería Metalúrgica y de Materiales, Universidad Técnica Federico Santa María, Av. España 1680, Valparaíso, Chile.

${ }^{5}$ Instituto de Química, Pontificia Universidad Católica de Valparaíso, Av. Universidad 330, Valparaíso, Chile.

${ }^{6}$ LISE, Sorbonne Universités, UPMC Univ Paris 06, CNRS, 4 place Jussieu, F75005 Paris, France

*Corresponding author. Email: mamiesancy@uc.cl (Mamié Sancy)

\section{Abstract}


Porous Ti-based alloys are currently considered for application in biomedical implants owing to similarity of their mechanical properties with those of human bone, potentially eliminating the risk of so-called stress shielding. In this work, Ti-30Nb-13Ta-2Mn at.\% porous alloy, also referred to as foam, was obtained by the powder metallurgy approach using $\left(\mathrm{NH}_{4}\right)_{2}\left(\mathrm{CO}_{3}\right)$ as space-holder. The foam samples were immersed to simulated body fluid after $504 \mathrm{~h}$ at $37^{\circ} \mathrm{C}$ and the effect of exposure was evaluated by using electrochemical techniques. In addition, microstructure was examined by means of scanning electron microscopy, X-ray diffraction, Archimedes method and nitrogen adsorption isotherms analyzed according to the Brunauer-Emmett-Teller theory. The results revealed two pore size distributions that are modified distinctively during exposure. Whereas macroporosity decreased consistently in time, microporosity evolved to a stable structure in the first hour of exposure to produce an active area of $0.57 \mathrm{~m}^{2} / \mathrm{g}$. The electrochemical analysis revealed a passive behavior evolving during exposure due to competitive formation and dissolution of corrosion products at the pores. It is concluded that macroporosity alone is insufficient for explaining corrosion performance of the alloy foam.

\section{Introduction}

The interests of biomedical industry in light-alloys foams has been motivated by their potential application in the ever greater prevalence of degenerative diseases, such as arthritis, arthrosis, and osteoporosis among others. The parts of human body that are mostly affected are the hip, knee, shoulder, and ankle 
[1], requiring replacement of the degeneratied part in order to avoid pain and restore the biological function. The number of the related surgical intervetions is at rise with the estimation of $174 \%$ growth for the primary total hip arthroplasty (THA), from 208,600 in 2005 to 572,000 by 2030 , and staggering $673 \%$ for the primary total knee arthroplasty (TKA), from 450,000 in 2005 to 3.48 million procedures by $2030[1,2]$. At the same time, the increasing life expectancy requires that the impants may be implemented with minimum risk and maintain their reliability over a longer time. In particular, the physical and mechanical properties of the implant would ideally be in agreement with the native bone tissue, not only in terms of mechanical strength or flexibility but also biocompatibility, allowing for osteointegration and sustained bio-functionality [3]. Further, it should be considered that any product of materials degradation may cause inflammation, allergic reactions possibly compromising the normal function of the implant or even be released to the blood flow [4].

The alloys that are conventionally used for joint implants include $316 \mathrm{~L}$ stainless steels (316LSS), Co-Cr alloys and Ti-based alloys. Although the first two options have been preferred for their widely tested biocompatibility (and also the ecomic aspect), their mechanical properties are far from compatible with elastic modulus of about $200 \mathrm{GPa}$ as compared with 2 to $30 \mathrm{GPa}$ of the hard bone tissue. Whereas, Ti-based alloys have elastic modulus closer to that of human bone and additionally display low density, high specific strength, biocompatibility and good corrosion resistance [1-4]. The first generation of Ti-alloys featured $\mathrm{Al}, \mathrm{V}, \mathrm{Ni}$ and $\mathrm{Co}$ as alloying elements that improved significantly the mechanical properties but produced toxic effect upon the event of (tribo)corrosion. Second 
generation alloys have been developed non-toxic alloying elements, such as $\mathrm{Nb}, \mathrm{Mo}$, and/or $\operatorname{Zr}[3-16]$.

Independent of the type alloy, a further opportunity for improving the short- and long-term bio-functional performance of an implant is by introduction of porosity. The presence of pores reduces the elastic modulus and, in case of interconnected porosity, allows for a stable long-term fixation by increasing the effective surface area at which osteointegration can take place. Pore size, pore shape and porosity are crucial to the process of osteogenesis $[17,18]$. However, the increase of the porosity in the metallic alloy implies the increase of the active surface area to be in effective contact with the surrounding body fluid, which in case of release and build-up of corrosion product increases the risk of aseptic failure as compared with a bulk alloy. Although total joint replacements for osteoarthritis and rheumatoid arthritis are effective interventions, release of corrosion products and wear debris remain the major factor limiting their time of service with signs and symptoms often not being clinically apparent until late stages of tissue destruction.

Up to now, electrochemical studies on porous Ti-based alloys focused on identifying the relation between porosity and corrosion performance. Alves et al [19] observed that a variety of Ti-alloy concepts fabricated by the powder metallurgy technique increase in corrosion current $\left(I_{\text {corr }}\right)$ is associated with higher porosity. Fangxia Xie et al. [20,21] studied Ti-xMo porous alloys ( $\mathrm{x}$ taking values of 4,6 , or 8 wt.\%) obtained by selective laser sintering observing that lower porosity correlates with a shift of corrosion potential $\left(E_{\text {corr }}\right)$ in the anodic direction and reduction in $\mathrm{I}_{\text {corr }}$, which was interpreted as increased corrosion 
resistance. As compared with their bulk counterparts, porous materials were shown to be generally more susceptible to electrochemical degradation, explained by a larger effective surface area determined by the size and morphology of the interconnected pores. Although bulk alloys provide better corrosion performance, the requirement of elastic modulus and technological implications of producing bulk alloys, porous alloys remain attractive for biomedical applications.

The main goal of the present work is to extend the understanding of the electrochemical behavior of a Ti-based alloy with a porosity grade close to $40 \%$ after being exposed to a simulated blood plasma fluid. Electrochemical measurements and surface analytical techniques are employed along with microstructural characterization at two levels of pore hierarchy, i.e. macro- and micropores.

\section{Experimental}

\subsection{Samples}

Alloy foams of Ti-30Nb-13Ta-2Mn at.\% were fabricated through the powder metallurgy technique with space holder, using elemental powders of $\mathrm{Ti}(99.5 \%$, $<45 \mu \mathrm{m}, \mathrm{NOAH}$ Technologies), Nb (99.9\%, <44 $\mu \mathrm{m}, \mathrm{NOAH}$ Technologies), Ta (99.9\%, <44 $\mu \mathrm{m}, \mathrm{NOAH}$ Technologies) and Mn $(99.9 \%,<44 \mu \mathrm{m}, \mathrm{NOAH}$ Technologies). The powders were mechanically alloyed in a RETSCH PM400 ball mill for the effective duration of $50 \mathrm{~h}$, under protective Ar atmosphere and ball to powder weight ratio of 10:1. The alloy powder was then mixed with the 
desired volume fraction of $\left(\mathrm{NH}_{4}\right)_{2} \mathrm{CO}_{3} 50$ wt.\% serving as space holder. Rod test samples with $8 \mathrm{~mm}$ of diameter were produced by uniaxial pressing to $400 \mathrm{MPa}$ and thermal treatment of the resulting cylinders for $3 \mathrm{~h}$ at $1250{ }^{\circ} \mathrm{C}$ under protective Ar-atmosphere. The foam sample surfaces were mechanically polished with SiC paper ranging from 320 to 2000 grits followed by diamond paste $(3$ and $1 \mu \mathrm{m})$ on a polishing cloth to obtain a mirror surface. Later, each polished sample was rinsed with acetone and was put in an ultrasonic cleaner for 10 min. Finally, it was rinsed with distilled water and dried in air at room temperature.

\subsection{Microstructural and mechanical characterization}

The morphology of microstructure was evaluated by a field emission-scanning electron microscope (FE-SEM, QUANTA FEG 250) equipped with energy dispersive spectrometer. To determine the macroporosity of the foams the Archimedes principle was employed according to the Standard Test Method ASTM C373-88. The active area associated with the microporosity of the foams was determined using Brunauer-Emmett-Teller (BET) equation (BET, 3-FLEX). The crystalline phases were evaluated prior and after exposure to simulated body fluid (SBF) by means of X-Ray powder diffraction (XRD) using a multipurpose powder diffractometer STOE STADI MP equipped with a DECTRIS MYTHEN $1 \mathrm{~K}$ detector and operated with Cu $\mathrm{K}_{\alpha 1}$-source $(\lambda=1.54056$ $\AA$ ). Mechanical strength of the foams in the elastic range of deformation was estimated employing the Gibson-Ashby model [22], which relates elastic modulus $(E)$ and relative density $(\rho)$ of a porous metal by Eq. (1) 


$$
E=C E_{s}\left(\frac{\rho}{\rho_{s}}\right)^{2}
$$

where $C, E_{S}$ and $\rho_{s}$ are a phenomenological constant, elastic modulus of the bulk alloy (non-porous), and density of the bulk alloy, respectively.

\subsection{Exposure and electrochemical characterization}

For the electrochemical measurements, a three-electrode cell was used with a graphite rod as counter and saturated calomel electrode (SCE) as reference electrode. A rod of Ti-30Nb-13Ta-2Mn at. $\%$ alloy foam of $0.28 \mathrm{~cm}^{2}$ crosssectional exposed geometrical area was used as working electrode and was mounted in a rotating disc electrode kit (OrigaTrod, Origalys). The electrolyte was a SBF corresponding to a Ringer's solution with chemical composition in g/L: $9.00 \mathrm{NaCl}, 0.43 \mathrm{KCl}, 0.20 \mathrm{NaHCO}_{3}$, and $0.24 \mathrm{CaCl}_{2}$. The test cell was maintained at a constant temperature of $37 \pm 1^{\circ} \mathrm{C}$ f or the duration, which was either 2, 24, 72, 168, 336 or 504 hours. Electrochemical measurements were carried out using potentiostat/galvanostat (VSP, Biologic). Anodic and cathodic polarization curves were obtained at a scan rate of $0.1 \mathrm{mV} \cdot \mathrm{s}^{-1}$ starting from $\mathrm{E}=$ $\mathrm{OCP}-50 \mathrm{mV}$ to $0 \mathrm{~V}$ vs SCE. The electrochemical impedance measurements were obtained at $\mathrm{OCP}$ and collected over a frequency range of $3 \mathrm{mHz}$ to $20 \mathrm{kHz}$ with eight points per decade using $10 \mathrm{mV}$ peak-to-peak sinusoidal voltage for the experiments. The impedance diagrams were analyzed by regression procedure based on a simplex strategy with a home-developed software (Simad).

\section{Results and discussion}




\subsection{Morphological and mechanical characterization}

The SEM micrographs in Figure 1 display a random structure of the alloy foam's porosity with observable distribution of pore sizes and irregular shape of individual pores. Prior exposure to SBF, the predominant pore size observed visually is below $10 \mu \mathrm{m}$ with scare presence of larger pores (> $50 \mu \mathrm{m})$; however, all of the porosity seems to be interconnected. The smaller pores especially well visible in Fig. 1B are typical to sintered metal, whereas the larger pores correspond to the size of carbonate space-holder vaporized in the process (see Figure $1 \mathrm{~A}$ and $1 \mathrm{~B})$. After exposure, characteristics of the porosity are visibly changed in that the smaller pores become smaller and the number of the larger pores increases. The apparent decrease of the smaller pores might be attributed to the deposition of corrosion products, which is supported by the little modification of micropores' appearance observed at longer time of exposure (see Figure $1 \mathrm{C}$ to $1 \mathrm{~F}$ ).

The change of porosity with time of exposure is also observed quantitatively in the values obtained by the Archimedes method and shown in Fig. 2. In the initial stage of exposure (below $200 \mathrm{~h}$ ), porosity first decreases and then increases indicating also a possible build-up of corrosion products at the interior of the pores. However, the accumulated amount is not constant in time and an occasional increase in porosity may be observed when a thinner layer is present or a possible corrosion products dissolution reaction take place. For the longer exposure times, a slight decrease of the porosity was observed which could indicate a passive film formation on the metallic foam that is in agreement with the SEM micrographs shown in Fig. 1. 
The active area and distribution of pore size with pore volume as estimated by the BET equation is shown in Fig. 3. The shape of the isotherm is indicative to macroporous materials [23], i.e. pore sizes $>50 \mathrm{~nm}$, according to IUPAC classification. Although the method is not suitable for quantifying the larger pores observed in the SEM micrographs, it is the smaller pores that make most of the effective surface area at which electrochemical reactions take place. Considering the low adsorption behavior of the $\mathrm{N}_{2}$ in the specific surface area of the foam, the active area determined by the BET equation was $0.57 \mathrm{~m}^{2} / \mathrm{g}$, which is attributed to the microporosity of the alloy. From this data, the active area participating in electrochemical reactions was estimated for the foam mass of $0.85 \mathrm{~g}$ considering that $3 / 5$ of the cylinder's height was immersed. The resulting $3000 \mathrm{~cm}^{2}$ was then used for analysis of electrochemical data. This value is assumed to be valid for all times of exposure, although minor deviation is possible due to corrosion of the metallic surface and/or formation of corrosion products. On the other hand, the existence of pores larger than $50 \mathrm{~nm}$ is not excluded (Fig. 3B), which is consistent with the SEM micrographs shown in Fig. 1. Mechanical properties of the alloy foams were quantified to verify compatibility with natural bone tissue. The elastic modulus estimated by Eq. (1) for $C=1$ $[24,25], E_{s}=147.98 \mathrm{GPa}$ and $\rho_{s}=12.1 \mathrm{~g} / \mathrm{cm}^{3}$, yielded $12.95 \pm 1 \mathrm{GPa}$, which is consistent with $15 \mathrm{GPa}$ reported for foams of similar composition and porosity [25], the difference being attributed to the bimodal structure specific to the material used in this study. However, the difference is irrelevant considering elastic moduli reported for femur human bone are in the range between 8.69 
and $18 \mathrm{GPa}[26,27]$, and proving the Ti-30Nb-13Ta-2Mn foam mechanically suitable for biomedical applications [28].

\subsection{Electrochemical results}

The effective surface area, i.e. the active area used for interpretation of the electrochemical data was estimated from the BET surface area as described previously. Figure 4A shows a Nyquist diagrams obtained from electrochemical impedance spectrum of the alloy foam recorded after the longest exposure time at $E=O C P$. The shape of the curve represent a typical impedance response of a porous electrode consisting of a metal in passive state [29]. The interfacial impedance can be associated with the impedance of an oxide layer which, in turn, can be represented approximately by a constant phase element (CPE) behavior [30]. In case of a porous electrode, the simplest approach is to employ the de Levie model, developed for the simplified geometry of cylindrical pores of equal length. The impedance of which may be described by (Eq. 2):

$$
Z_{\text {pore }}=\left(R_{0} Z_{0}\right)^{1 / 2} \operatorname{coth}\left(\ell \sqrt{\frac{R_{0}}{Z_{0}}}\right)
$$

where $R_{0}$ (in $\Omega \mathrm{cm}^{-1}$ ) and $Z_{0}$ (in $\Omega \mathrm{cm}$ ) are the electrolyte's resistance and the interfacial impedance for a one-unit length pore, respectively [29-32]. However, by applying this formula with $Z_{0}=\frac{1}{Q(j \omega)^{\alpha}}$, where $\mathrm{Q}$ and $\alpha$ are CPE parameters, it is not possible to regress with confidence over the entire frequency range. In fact, it is only suitable for describing the high frequency range (HF), in which the pore's impedance reduces to Eq. 3: 


$$
Z_{\text {pore }}=\left(R_{0} Z_{0}\right)^{1 / 2}
$$

A good quality of adjustment was obtained for the experimental data in the frequency range between $13 \mathrm{kHz}$ and $0.13 \mathrm{~Hz}$ (see Fig. 4A) (and fit parameters of $R_{e}=56.8 \Omega, Q / R_{0}=1.810^{-4} \mathrm{~F} / \Omega \mathrm{s}^{(1-\alpha)}, \alpha=0.7$ and $\chi^{2}=0.7$, where $\chi^{2}$ is a goodness of fit test. Although the fit is of satisfying quality, it should be kept in mind that the model describes an average geometry, which is not the case of the material studied here. The complexity of the porosity and its effect on the electrochemical response can be observed on the corrected Bode plot, as shown Fig. 5, where the phase shift does not follow a monotonic tendency over the entire range of frequency. The effect of the porosity on the impedance response may be also seen in Figure. S1 of the Supplementary Material, in which a comparison of impedance response is provided between the same alloy produced with and without space holder and thus containing bimodal and microporosity, respectively. For this reason, a different model is employed for fitting the very low frequency (VLF) range. In this case the impedance is described by Eq. 4 according to Lasia [32]:

$$
Z_{\text {pore }}=R_{\text {pore }}+\frac{1}{Q(j \omega)^{\alpha}}
$$

The five points measured in VLF range (between $3 \mathrm{mHz}$ and $9.5 \mathrm{mHz}$ ) are well fitted by the previous formula. The fitted parameters are: $R_{\text {pore }}=106.1 \Omega, Q=$ $0.1211 \mathrm{~F} / \mathrm{s}^{(1-\alpha)}, \alpha=0.90, \chi^{2}=1.09$. Fit parameters obtained for the all the exposure time are summarized in Tab. 1 . The fact that the $\alpha$ values obtained in the HF and VLF ranges are different indicates that the de Levie model is not applicable directly. This is again explained by the irregular pore geometry, 
which unlike the de Levie model assuming cylindrical pore shape, is too complex to be described by a simple analytical function. However, it is possible to consider that in the VLF range the impedance of the pore is the impedance of a plane electrode with a surface corresponding to the value estimated from BET surface area. Note that $Q$ and $\alpha$ values were obtained as was described in Ref 30 and the values are in agreement with a passive oxide layer with a thickness of few nanometers, as shown Table 1. Further, the resistance of pores, $R_{\text {pore }}$, may be expressed by:

$$
R_{\text {pore }}=\frac{\rho_{s} \ell}{3 n \pi r^{2}}
$$

where $n$ is the number of pores. As shown Table $1, R_{\text {pore }}$ decreased with time of exposure. If the pore geometry is not changing with time of exposure, then the resistivity in the pores $\rho_{\mathrm{s}}$ is also decreasing with time, which is agreement with an increase of ion concentration inside the pores due to the metal corrosion.

Table 1: Impedance fit parameters of Ti-30Nb-13Ta-2Mn alloy after exposure to SBF solution.

\begin{tabular}{|c|c|c|c|}
\hline $\mathrm{t} / \mathrm{h}$ & $\mathrm{R}_{\text {pore }} / \Omega$ & $\mathrm{Q} / \mathrm{F} /\left(\mathrm{cm}^{2} \mathrm{~s}^{1-\alpha}\right)$ & $\alpha$ \\
\hline 2 & 182.0 & $1.1 \cdot 10^{-5}$ & 0.93 \\
\hline 24 & 151.5 & $6.6 \cdot 10^{-6}$ & 0.85 \\
\hline 72 & 155.0 & $2.9 \cdot 10^{-5}$ & 0.86 \\
\hline 168 & 110.5 & $2.9 \cdot 10^{-5}$ & 0.85 \\
\hline 336 & 112.0 & $4.0 \cdot 10^{-5}$ & 0.88 \\
\hline 504 & 106.1 & $4.1 \cdot 10^{-5}$ & 0.90 \\
\hline
\end{tabular}

On the other hand, polarization curves recorded after impedance spectroscopy (Fig. 6) corroborate the passive behavior of metal after all the times of exposure; although a shift of the corrosion potential $\left(E_{\text {corr }}\right)$ in the cathodic 
direction is observed, as well as a slight increase of the anodic current density for shorter time of exposure and its decrease for the longer exposure times (see insert in Fig.6). Considering the results of EIS analysis, the modulation of anodic current indicates an ongoing competition between formation and dissolution of corrosion products along the time of exposure. It should be noted that the polarization test might have an effect on the response of the sample, as shown Figure. S2 of the Supplementary Material, which shows that the impedance response was modified that might be attributed to evolution of the corrosion process and passive oxide film. This is consistent with the lowcrystallinity products and justifies the necessity of testing parallel samples rather than returning to expose samples that were already tested.

\subsection{XRD analysis}

Figure 7 compares XRD patterns recorded prior and after exposure to SBF. In the initial microstructure $(t=0 h)$ reflections of Ti-based solid solutions are identified corresponding to crystal structures typical to $\beta$-phase $(\mathrm{Im}-3 \mathrm{~m})$ and $\alpha$ phase $(\mathrm{P} 63 \mathrm{~mm} / \mathrm{c})$. In addition, reflections corresponding to three distinctive titanium oxides are found: $\mathrm{TiO}, \mathrm{TiO}_{2}$ and $\mathrm{Ti}_{2} \mathrm{O}_{3}$, with crystal structure of $\mathrm{Fm}-3 \mathrm{~m}$, Pbca and R-3c, respectively. These titanium oxides are typical to high temperature exposure during the sintering process. Although sintering was conducted in $\mathrm{Ar}$ atmosphere, exposure of the metallic precursors to oxygen prior mechanical alloying and oxygen impurity of the protective gas is sufficient for the oxide formation due to high reactivity of $\mathrm{Ti}$. There are no $\mathrm{Nb}$ or Ta oxides observed in the diffraction pattern indicating the formation of solid solution with 
the $\mathrm{Ti}$ matrix. After $336 \mathrm{~h}$ of exposure the peaks corresponding to high temperature oxide are not observed; whereas in addition to the Ti-alloy phases and additional peaks are found corresponding to titanium carbide (TiC) with cubic crystal structure cF8 (Fm3m). Further, a decrease in the intensity of the $\alpha$-phase reflections is observed, which is explained by its relatively higher susceptibility to corrosion as compared with the $\beta$-phase [33] and sustained by the emergence of $\mathrm{TiC}$ as corrosion product due to presence of carbon in the SBF solution. Finally, there are no crystalline phases of oxides or hydroxides after exposure indicating that these corrosion products, evidenced by the electrochemical analysis, are either present in very small fraction of volume or the remain amorphous. This last observation is consistent with the effect of polarization testing on the impedance response (Figure. S2).

\section{Conclusion}

In this study, electrochemical evaluation of porous Ti-30Nb-13Ta-2Mn in long term exposure to simulated body fluid was conducted in the context of microstructure evolution in the process. The as-sinterized random pore structure of the alloy foam, consisting of interconnected pores of irregular shape and two pore size distributions corresponding to macro- and micropores, was found to be affected distinctively at the two levels of hierarchy. Whereas the macropores increased in number and size incrementing porosity in time, the micropores were stabilized in the first hours of exposure. The electrochemical response was found to be mostly determined by the competitive processes of formation and dissolution of corrosion products at the pores' walls as 
demonstrated by EIS. The analysis revealed the complexity of the porous electrodes that questions the possibility of direct correlation between porosity and corrosion performance due inhomogeneity of the passive film at the inner surface that is determined not only by the pore volume.

\section{Acknowledgements}

The authors would like to acknowledge the support of National Commission for Scientific and Technological Research (CONICYT) through FONDECYT Grant No. 1160604, FONDEQUIP EQM160070 and PIA-CONICYT Grant 1412.

\section{References}

[1] M. Geetha, A.K. Singh, R. Asokamani, A.K. Gogia, Ti based biomaterials, the ultimate choice for orthopaedic implants - A review, Prog. Mater. Sci. 54 (2009) 397-425. doi:10.1016/j.pmatsci.2008.06.004.

[2] S. Kurtz, K. Ong, E. Lau, F. Mowat, M. Halpern, Projections of Primary and Revision Hip and Knee Arthroplasty in the United States from 2005 to 2030, 2007. doi:10.2106/00004623-200704000-00012.

[3] P. Silva-Bermudez, S.E. Rodil, An overview of protein adsorption on metal oxide coatings for biomedical implants, Surf. Coatings Technol. 233 (2013) 147-158. doi:10.1016/j.surfcoat.2013.04.028.

[4] M. Ruzickova, H. Hildebrand, S. Virtanen, On the Stability of Passivity of Ti-Al Alloys in Acidic Environment, 2005.

doi:10.1524/zpch.2005.219.11.1447. 
[5] Ministerio de Salud Chile, Guía Clínica Tratamiento Médico en personas de 55 años y mas con Artrosis de Cadera y/o rodilla, Minist. Salud Chile. (2009) pp 4-33.

[6] H. Cruz, J. Souza, M. Henriques, L. Rocha, Tribocorrosion and BioTribocorrosion in the Oral Environment: The Case of Dental Implants, 2011.

[7] D.F. Williams, On the mechanisms of biocompatibility, Biomaterials. 29 (2008) 2941-2953. doi:10.1016/j.biomaterials.2008.04.023.

[8] E. Eisenbarth, D. Velten, M. Müller, R. Thull, J. Breme, Biocompatibility of $\beta$-stabilizing elements of titanium alloys, Biomaterials. 25 (2004) 57055713. doi:10.1016/j.biomaterials.2004.01.021.

[9] X. Wang, Y. Li, J. Xiong, P.D. Hodgson, C. Wen, Porous TiNbZr alloy scaffolds for biomedical applications, Acta Biomater. 5 (2009) 3616-3624. doi:10.1016/j.actbio.2009.06.002.

[10] C.E. Wen, Y. Yamada, K. Shimojima, Y. Chino, H. Hosokawa, M. Mabuchi, Novel titanium foam for bone tissue engineering, J. Mater. Res. 17 (2002) 2633-2639. doi:10.1557/JMR.2002.0382.

[11] D.F. Williams, On the nature of biomaterials, Biomaterials. 30 (2009) 5897-5909. doi:10.1016/J.BIOMATERIALS.2009.07.027.

[12] F. Variola, J. Brunski, G. Orsini, P.T. De Oliveira, A. Nanci, Nanoscale surface modifications of medically-relevant metals: state-of-the art and perspectives, Nanoscale. 3 (2012) 335-353.

doi:10.1039/c0nr00485e.Nanoscale.

[13] D.M. Dohan Ehrenfest, P.G. Coelho, B.-S. Kang, Y.-T. Sul, T. 
Albrektsson, Classification of osseointegrated implant surfaces: materials, chemistry and topography, Trends Biotechnol. 28 (2010) 198-206. doi:10.1016/J.TIBTECH.2009.12.003.

[14] M.-J. Han, H.-C. Choe, C.-H. Chung, Surface characteristics of clinically used dental implant screws, Met. Mater. Int. 11 (2005) 449-456. doi:10.1007/BF03027494.

[15] D. Martini, M. Fini, M. Franchi, V.D. Pasquale, B. Bacchelli, M. Gamberini, A. Tinti, P. Taddei, G. Giavaresi, V. Ottani, M. Raspanti, S. Guizzardi, A. Ruggeri, Detachment of titanium and fluorohydroxyapatite particles in unloaded endosseous implants, Biomaterials. 24 (2003) 1309-1316. doi:10.1016/S0142-9612(02)00508-2.

[16] M. Nakagawa, S. Matsuya, T. Shiraishi, M. Ohta, Effect of Fluoride Concentration and $\mathrm{pH}$ on Corrosion Behavior of Titanium for Dental Use, J. Dent. Res. 78 (1999) 1568-1572. doi:10.1177/00220345990780091201.

[17] N. Schiff, B. Grosgogeat, M. Lissac, F. Dalard, Influence of fluoride content and $\mathrm{pH}$ on the corrosion resistance of titanium and its alloys, Biomaterials. 23 (2002) 1995-2002. doi:10.1016/S0142-9612(01)003283.

[18] X.H. Wang, J.S. Li, R. Hu, H.C. Kou, Mechanical properties and pore structure deformation behaviour of biomedical porous titanium, Trans. Nonferrous Met. Soc. China (English Ed. 25 (2015) 1543-1550. doi:10.1016/S1003-6326(15)63756-6.

[19] A.C. Alves, I. Sendão, E. Ariza, F. Toptan, P. Ponthiaux, A.M.P. Pinto, 
Corrosion behaviour of porous Ti intended for biomedical applications, J. Porous Mater. 23 (2016) 1261-1268. doi:10.1007/s10934-016-0185-0.

[20] F. Xie, X. He, S. Cao, M. Mei, X. Qu, Influence of pore characteristics on microstructure, mechanical properties and corrosion resistance of selective laser sintered porous Ti-Mo alloys for biomedical applications, Electrochim. Acta. 105 (2013) 121-129.

doi:10.1016/j.electacta.2013.04.105.

[21] Y.-H. Li, N. Chen, H.-T. Cui, F. Wang, Fabrication and characterization of porous Ti-10Cu alloy for biomedical application, J. Alloys Compd. 723 (2017) 967-973. doi:10.1016/J.JALLCOM.2017.06.321.

[22] J.W.H. and H.N.G.W. M.F. Ashby, A.G. Evans, N.A. Fleck, L.J. Gibson, Metal Foams : A Design Guide Metal Foams : A Design Guide, (n.d.).

[23] M. Lawrence, Y. Jiang, Porosity, pore size distribution, micro-structure, in: RILEM State-of-the-Art Reports, Springer, Dordrecht, 2017: pp. 39-71. doi:10.1007/978-94-024-1031-0_2.

[24] X. Rao, C.L. Chu, Y.Y. Zheng, Phase composition, microstructure, and mechanical properties of porous $\mathrm{Ti}-\mathrm{Nb}-\mathrm{Zr}$ alloys prepared by a two-step foaming powder metallurgy method, J. Mech. Behav. Biomed. Mater. 34 (2014) 27-36. doi:10.1016/J.JMBBM.2014.02.001.

[25] C. Aguilar, C. Guerra, S. Lascano, D. Guzman, P.A. Rojas, M. Thirumurugan, L. Bejar, A. Medina, Synthesis and characterization of TiTa-Nb-Mn foams, Mater. Sci. Eng. C. 58 (2016) 420-431. doi:10.1016/j.msec.2015.08.053.

[26] J.Y. Rho, R.B. Ashman, C.H. Turner, Young's modulus of trabecular and 
cortical bone material: Ultrasonic and microtensile measurements, J. Biomech. 26 (1993) 111-119. doi:10.1016/0021-9290(93)90042-D.

[27] R. Oftadeh, M. Perez-Viloria, J.C. Villa-Camacho, A. Vaziri, A. Nazarian, Biomechanics and mechanobiology of trabecular bone: a review., J. Biomech. Eng. 137 (2015) 108021. doi:10.1115/1.4029176.

[28] A.M.G. Tavares, W.S. Ramos, J.C.G. de Blas, E.S.N. Lopes, R. Caram, W.W. Batista, S.A. Souza, Influence of Si addition on the microstructure and mechanical properties of Ti-35Nb alloy for applications in orthopedic implants, J. Mech. Behav. Biomed. Mater. 51 (2015) 74-87. doi:10.1016/j.jmbbm.2015.06.035.

[29] A. Lasia, Electrochemical Impedance Spectroscopy and its Applications, Mod. Asp. Electrochem. 32 (1999) 143-248. doi:10.1007/0-306-469162\{\} 2$.

[30] M.E. Orazem, B. Tribollet, Electrochemical impedance spectroscopy, John Wiley \& Sons, 2017.

[31] F. Hilario, V. Roche, A.M. Jorge, R.P. Nogueira, Application of the transmission line model for porous electrodes to analyse the impedance response of TiO2nanotubes in physiological environment, Electrochim. Acta. 253 (2017) 599-608. doi:10.1016/j.electacta.2017.09.045.

[32] R. Jurczakowski, C. Hitz, A. Lasia, Impedance of porous Au based electrodes, J. Electroanal. Chem. 572 (2004) 355-366. doi:10.1016/J.JELECHEM.2004.01.008.

[33] J. Lu, P. Ge, Q. Li, W. Zhang, W. Huo, J. Hu, Y. Zhang, Y. Zhao, Effect of microstructure characteristic on mechanical properties and corrosion 
behavior of new high strength Ti-1300 beta titanium alloy, J. Alloys Compd. 727 (2017) 1126-1135. doi:10.1016/j.jallcom.2017.08.239. 

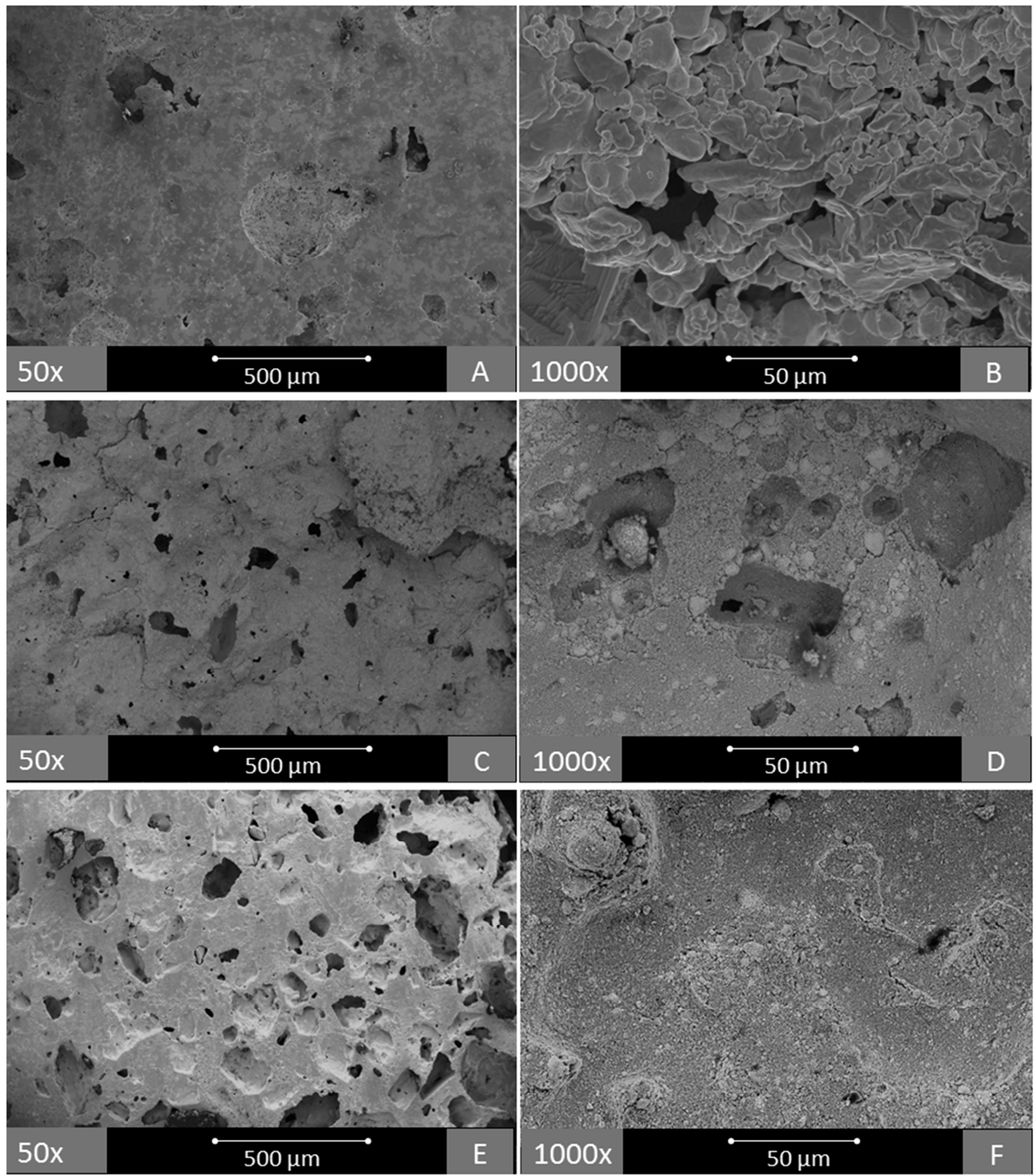

Figure 1: SEM micrographs of Ti-30Nb-13Ta-2Mn foams prior and after exposure to SBF solution at $37^{\circ} \mathrm{C}:(\mathrm{A})$ and $(\mathrm{B})$ correspond to the initial microstructure, (C) and (D) after 72 hours of exposure, $(E)$ and $(F)$ after 504 hours of exposure. 


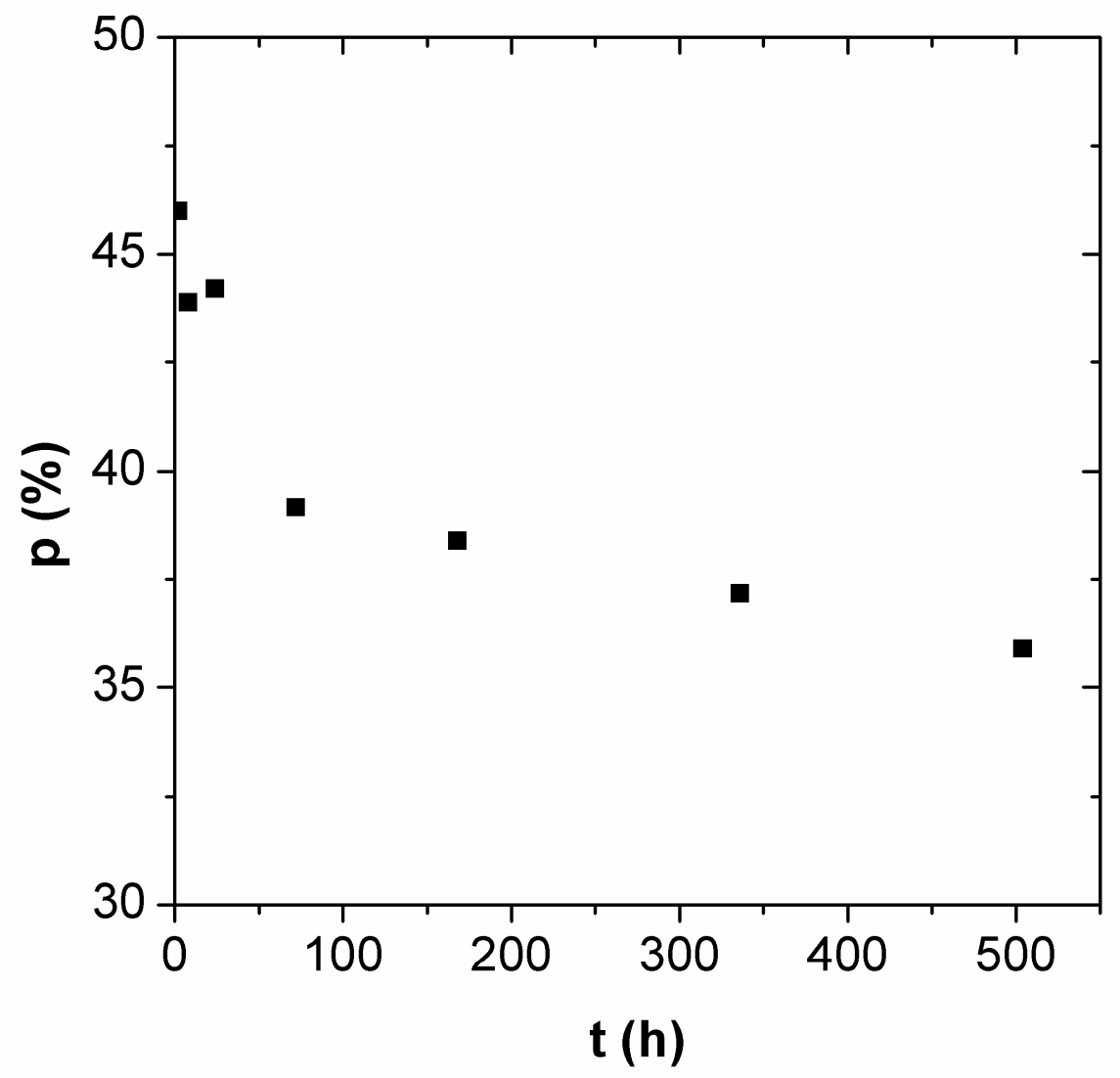

Figure 2: Porosity of Ti-30Nb-13Ta-2Mn foam in function of time of exposure to SBF solution at $37^{\circ} \mathrm{C}$ as determined by the Archimedes principle. 

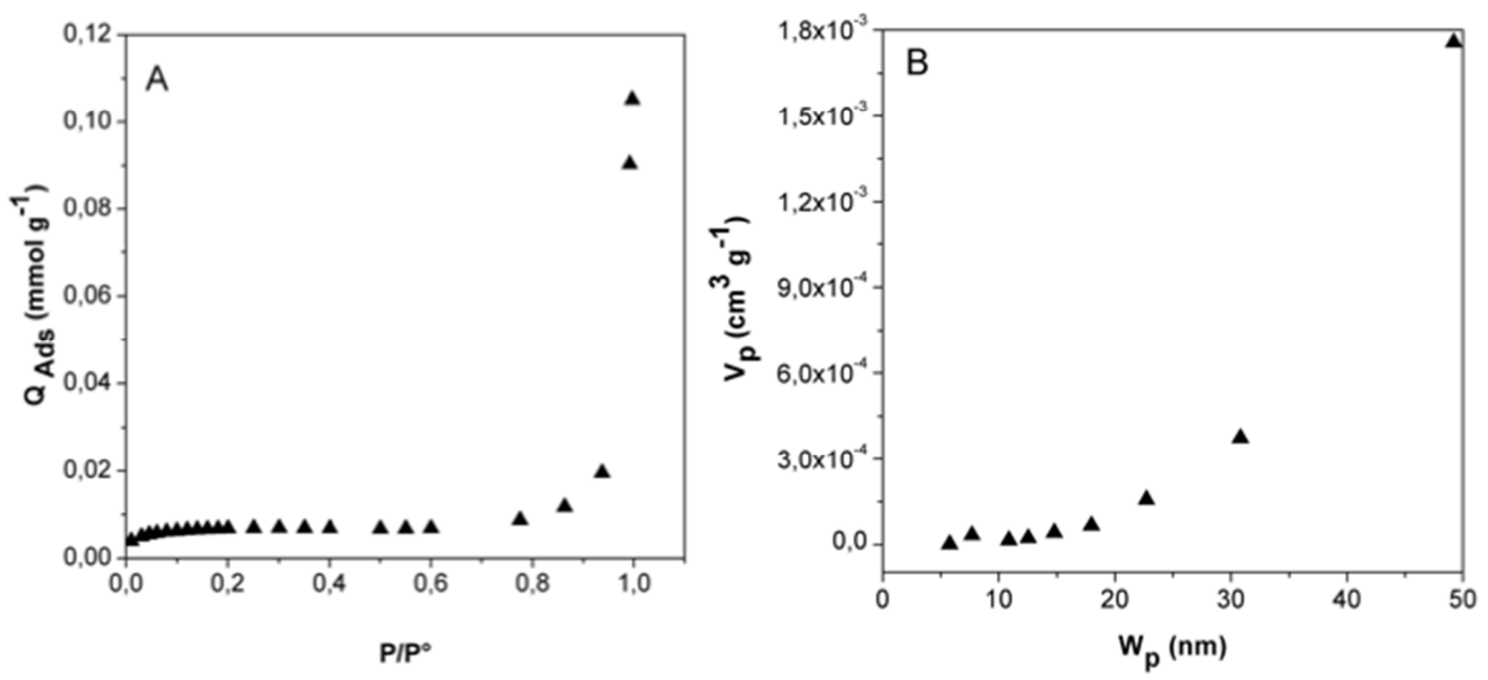

Figure 3: BET adsorption isotherm $(A)$ and calculated pore volume $(B)$ of Ti$30 \mathrm{Nb}-13 \mathrm{Ta}-2 \mathrm{Mn}$ foam after exposure to SBF for 72 hours. 

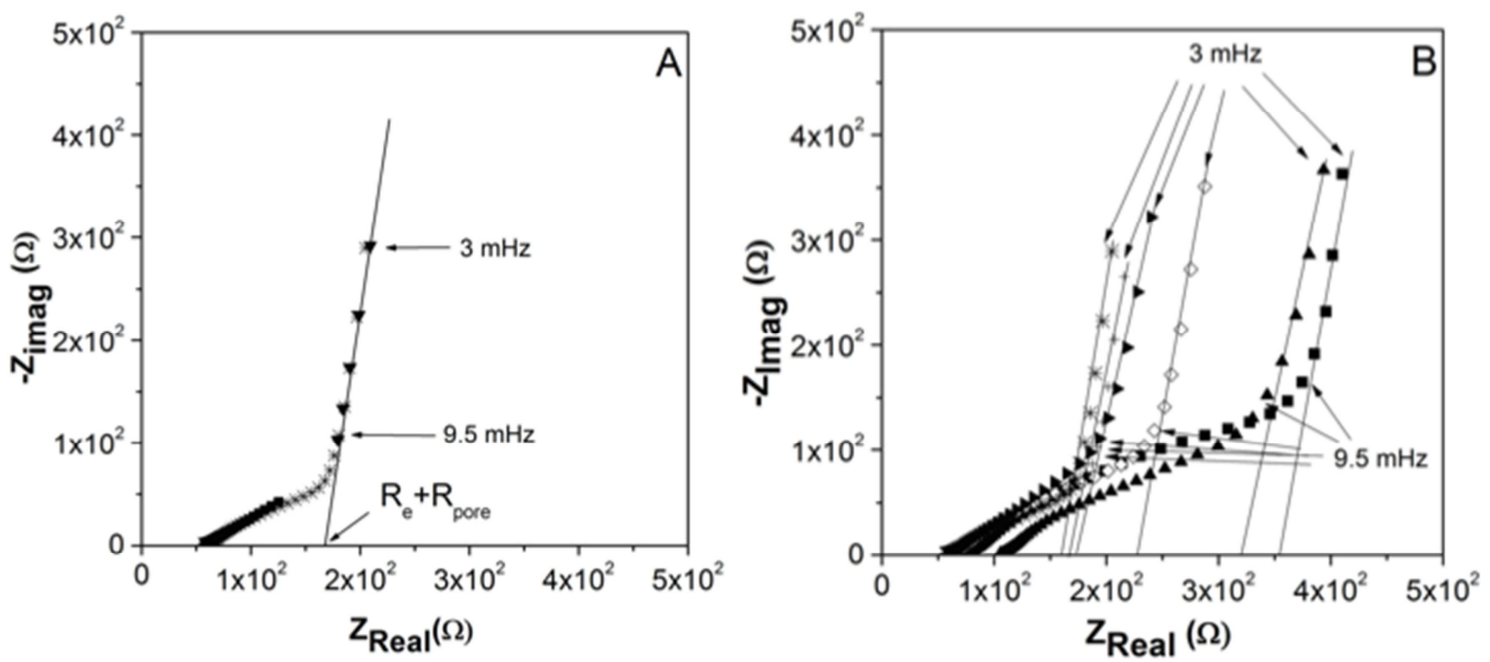

Figure 4: Nyquist diagrams of Ti-30Nb-13Ta-2Mn after being exposed in SBF solution at $37^{\circ} \mathrm{O}$. (A) correspond after 504 hours of exposure,

$(\mathbb{\square})$ Fitting in high frequency range, $(\boldsymbol{\nabla})$ fitting in very low frequency range and

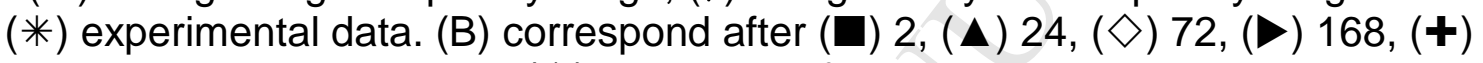
336 and (*) 504 hours of exposure time. 


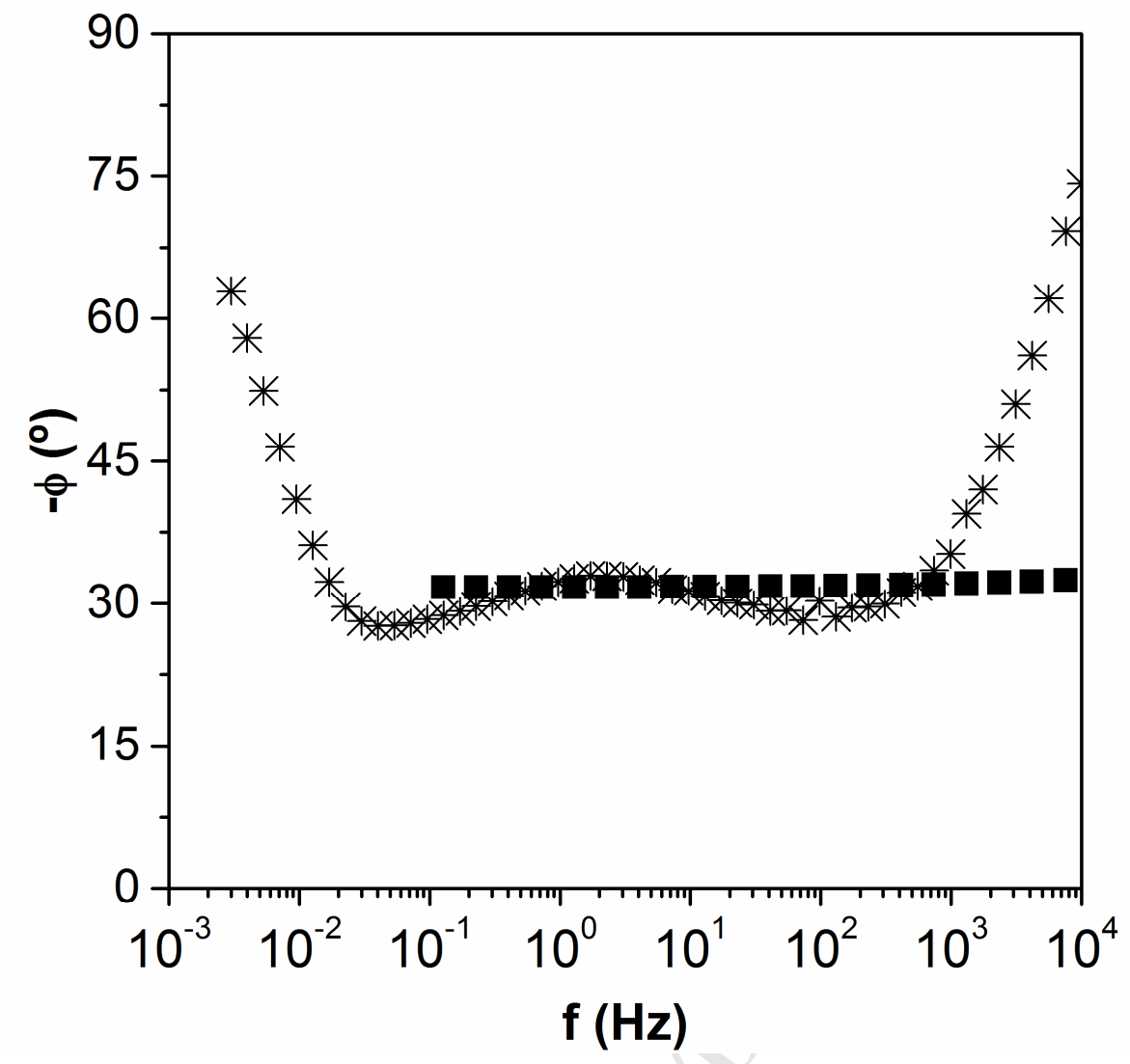

Figure 5: Phase of the corrected Bode plot of Ti-30Nb-13Ta-2Mn after 504 hours in SBF solution at $37^{\circ} \mathrm{C}$. (更) Fitting in high frequency range and (*) experimental data. 


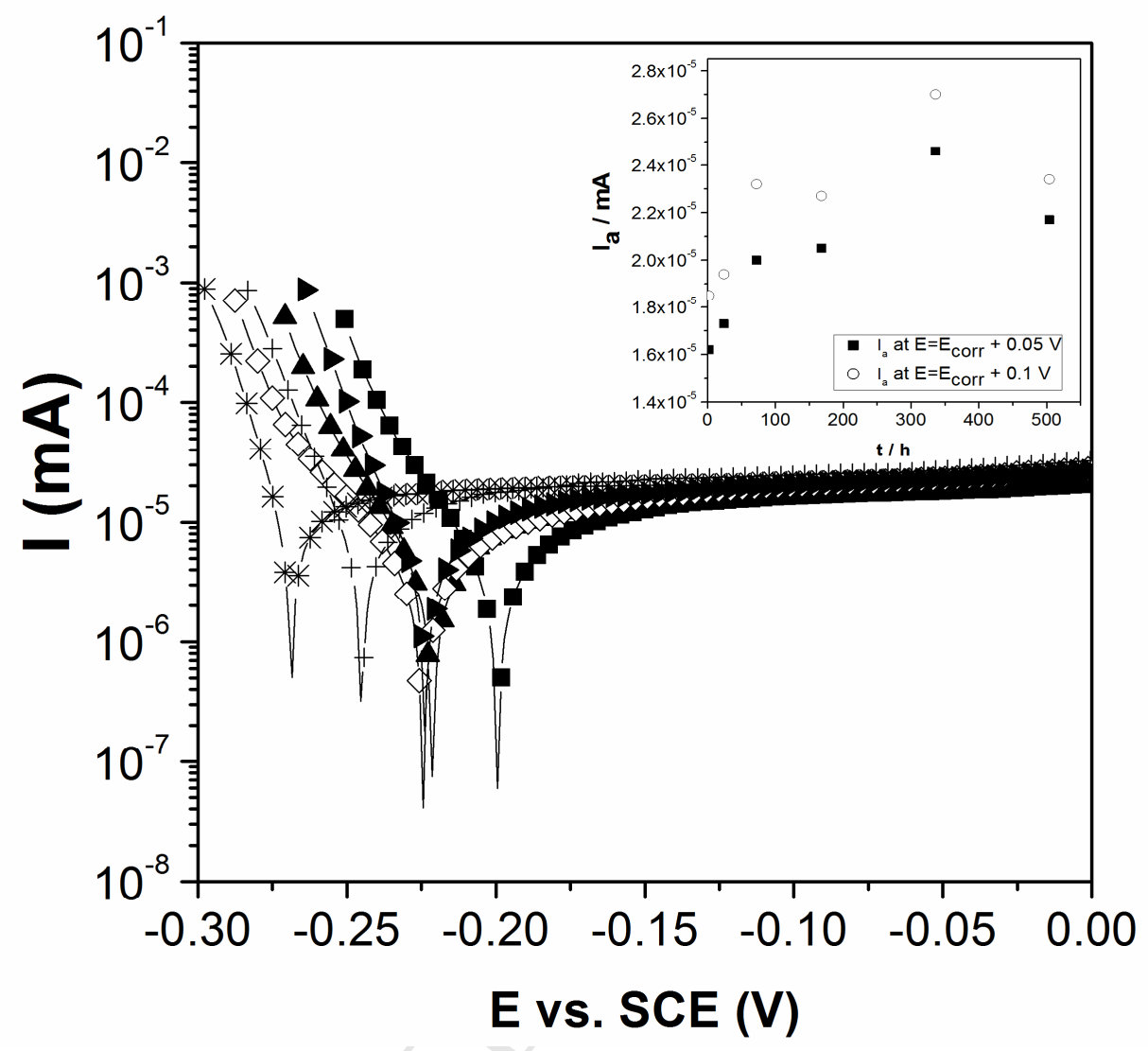

Figure 6: Polarization curves of Ti-30Nb-13Ta-2Mn as a function of exposure time in SBF solution at $37^{\circ} \mathrm{C}$. The insert shows associated anodic corrosion currents obtained from at $\mathrm{E}=0.05 \mathrm{~V}$ and $\mathrm{E}=0.1 \mathrm{~V}$ vs SCE.

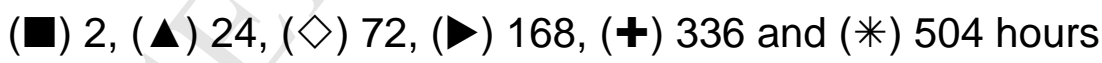




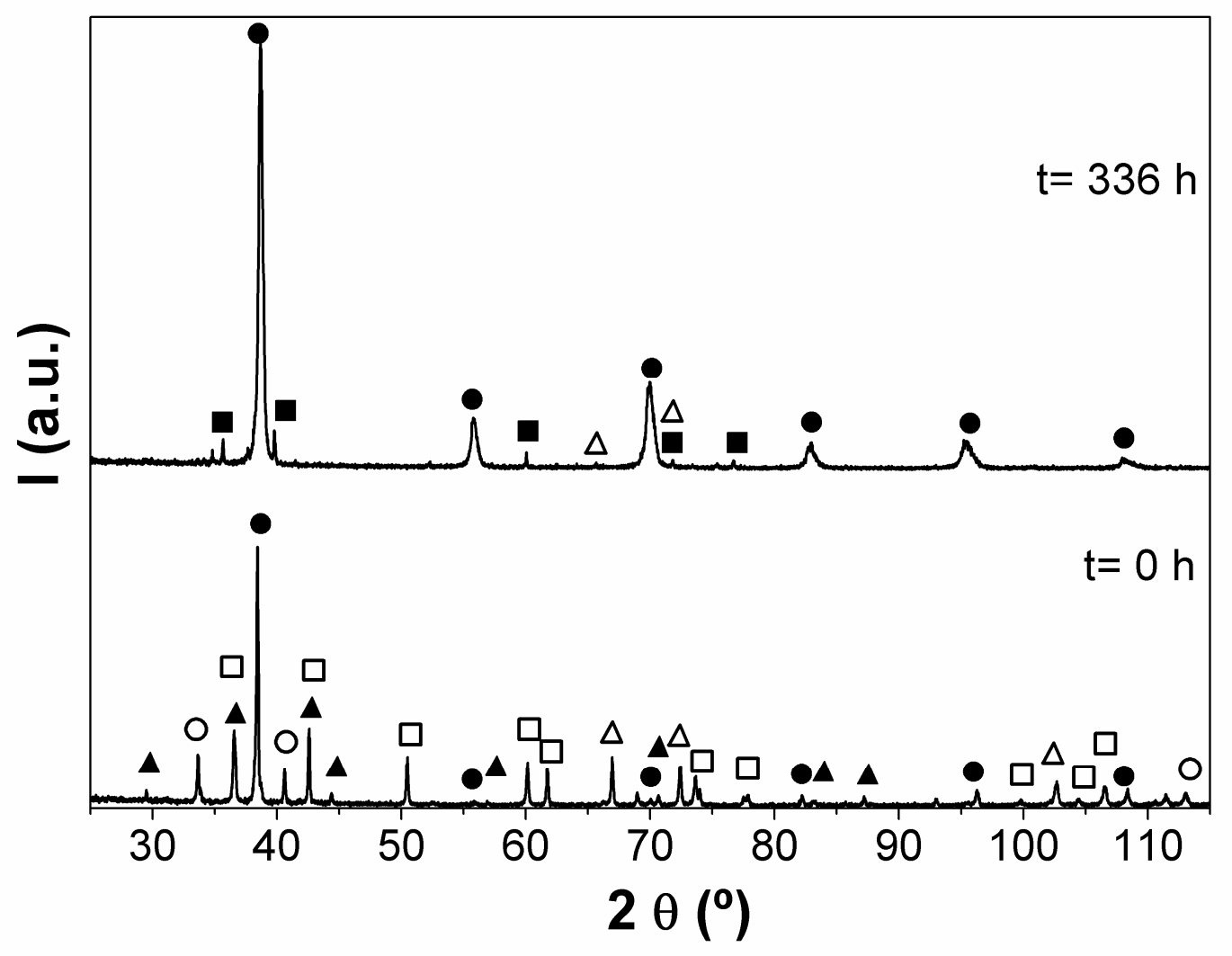

Figure 7: XRD patterns of Ti-30Nb-13Ta-2Mn prior and after 336 hours of exposure to SBF solution at $37^{\circ} \mathrm{C}$. ( $(\bullet)$-solution solid; $(\Delta) \alpha$-solution solid; ( $(\boldsymbol{\square})$ $\mathrm{TiC} ;(\mathbf{\Lambda}) \mathrm{TiO}_{2} ;(\square) \mathrm{TiO} ;(\mathrm{O}) \mathrm{Ti}_{2} \mathrm{O}_{3}$. 